\title{
MJN NURSES' EXPERIENCE OF CARING FOR CRIMINALS AT EMERGENCY DEPARTMENT
}

\author{
Wirmando $^{1,2}$, Asti Melani Astari ${ }^{1 *}$, Laily Yuliatun ${ }^{1}$ \\ ${ }^{1}$ Department of Nursing, Faculty of Medicine, University of Brawijaya, Malang, Indonesia \\ ${ }^{2}$ Stella Maris School of Health Sciences of Higher Education, Makassar, Indonesia \\ *Corresponding Author’s E-mail: astariasti.fk@ub.ac.id
}

\begin{abstract}
Introduction: Nurses have important roles in treating criminals. To treat the criminals is complex and it has different challenges. Nurses feel uncomfortable in treating an individual who have injured, raped, and murdered other individuals. They have difficulties to carry out caring principles in such an unsafe and dangerous situation with the risk of physical-attack that could influence their nursing practice and quality. Objective: To explore the nurses' experiences in caring for criminals at the emergency department. Methodology: It is qualitative research with a phenomenological approach. This research was conducted by carrying out in-depth interview of 10 nurses in the emergency department. The applied data analysis technique is the Interpretative Phenomenological Analysis (IPA). Results: The emerging themes in this research are awareness toward the obligation and responsibility as nurses, implementation of caring principle in treating the criminals, and having no intention for the police officers to get involved in the patients' treatment processes. Conclusion: Nurses need to internalize and reflect caring as the philosophy of nursing. It is also important to realize without care, the recovery process and the purpose of giving treatment will not be achieved.
\end{abstract}

Keywords: Caring, Criminals, Experiences, Nurse

\section{INTRODUCTION}

The criminality rate in the world is still very high. United Nations Office on Drug and Crime (2019) sates the criminality rate in 2015, in the United State of America, has reached \pm 24 million cases; in Europe, has reached 9 million cases; and in South-West Asia, it has reached \pm 35 million cases with the highest criminality rate all over South-West Asia as much as 336.652 cases in Indonesia. At the present day, $80-90 \%$ of criminals require medical treatments with health problems, such as mental disorder, infectious disease, chronic disease, surgery, and history of drug abuse. However, developing apprehension deals with the gap in administering health services in that population. Criminals usually are attached to stigma and discrimination from society, including the nurses (Dhaliwal \& Hirst, 2016; McConville et al., 2018; Melillo, 2009; Redgewell, 2010).

Nurses in an Emergency Department have important roles in administering health services for the criminals, started when they access the health facility until the referral process. Thus, the Emergency Department nurses have great responsibilities in treating those patients (Dhaliwal \& Hirst, 2016; Margalith et al., 2008). Nurses must administer health service, included in emergency state condition, surgery, and mental health service. So, nurses must have professionalism, proper caring attitude, and integrity in administering it. However, to engage the health administration for the criminals, nurses must be experienced to handle stress and danger. Nurses realize that their jobs have physical and psychological risks while treating criminals. Even nurses think that treating criminals is a stressful situation. Thus, it influences their caring behaviors that affect the treatment quality (Dhaliwal \& Hirst, 2016).

The security problem and emotional feeling factor are the hindrances for the nurses to apply caring and to foster therapeutic relation. This makes the nurses face difficulties in applying the caring for the patients, though it the philosophy of nursing. They must treat their patient sincerely and attentively to achieve the objective of a professional nursing service (Dhaliwal \& Hirst, 2016; Maeva \& Vaughn, 2001). Therefore, this 
research aims to explore the nurses' experiences in caring for criminals at Emergency Department.

\section{Aim}

This research aims to explore the nurses' experiences in caring for criminals in the emergency department

\section{METHODOLOGY}

It is qualitative research with a phenomenological approach. This research applies the Creswell (2014) theory. The theory suggests the participants are allowed to explore their subjective experiences while providing treatment for the criminals.

\section{Participant}

The participants were selected by using purposive sampling technique with the following criteria: 1) The participants must have treated criminals, 2) the participants have been working as the nurses at the ED at least fot1 year, 3) the nurses are willing to be the participants by signing the consent form, and 4) the participants are willing to be interviewed and recorded during the research. The numbers of the participants consisted of 10 nurses from the emergency unit. There were 6 male and 4 female nurses within the age interval of 27-42 years. The participants' year of services were foe 2-10 years.

\section{Data Collection}

This research applies the researchers as the main instruments. The data collection technique was done by in-depth interviews for 40 to 60 minutes with 10 participants. The applied interview guideline is the semi-structured interview guideline. The interviews were recorded using a voice recorder and complemented by field notes to document the non-verbal responses of the participants.

\section{Ethical considerations}

This research has been granted ethical worthiness from the ethical commission of Makassar-health polytechnic of the Health Ministry.

\section{Data Analysis}

Data analysis was done using the Interpretative Phenomenological Analysis (IPA) proposed by Smith \& Osborn (2007). The stages of the data analysis are: 1) read and re-reading, 2) initial noting, 3) developing emergent themes, 4) searching for connection across emergent themes, 5) moving to the next case, and 6) looking for patterns across cases.

\section{RESULTS}

The interpretation results are the main keywords of the participants. They were collected and those with similarities were grouped into certain categories. The categories were then grouped into several sub-themes. Then, they formed a theme. This research found 3 themes, they are:

\section{Awareness of the obligation and responsibility as nurses}

This theme describes that the participants recognize and understand that they have responsibilities upon their professions and those must be carried out while providing health care for each patient even the criminals.

This theme consists of 3 sub-themes; they are working based on the code and the nursing procedure. It is described in the following excerpt:

"The point is we provide health service for them based on our standard operating procedure and under our job descriptions." (P1). (Them: The criminals).

"We are nurses and we have ethics. We have the regulation to follow" (P2)

The second sub-theme is providing high service quality for the patients. It is described in the following excerpt:

"I follow my intuition to provide excellent service. I do my best to provide services for them" (P8) (Them: The criminals)

"I do what I can for the service. Usually, the criminals are thirsty so I gave them something to drink"(P5).

The third sub-theme is providing emergency state treatment for the criminals based on the triage procedure. It is described in the following excerpt:

"It means we do not need to see he is a criminal or not. Even if he is a criminal but he is in an emergency condition, he must be prioritized. Thus, in providing service we should ignore the patients'statuses" (P9.)

"To treat a gunshot wound, it depends on the types of the wound. It means we must observe its emergency level. So, we should see again how the patient's condition is" $(\mathrm{P} 7)$.

"Thus, treatment should be administered immediately. For example, if surgery is required, then it must be carried out immediately." (P10). 


\section{Practicing the caring in treating the criminals}

This theme describes that the participants practiced the caring principle sincerely for the criminals. The participants realize that the caring principle is a realization of concern action for the patients. It was realized by the participants that caring is a basic principle of a nurse as a profession. It must be owned by each nurse to always respect, to not discriminate, and to completely treat them even when the patients are criminals. The participant realized that by practicing the caring, the purpose of nursing would be achieved.

This theme consists of 3 sub-themes they are caring and behaving sincerely toward the criminals. It is described in the following excerpt:

"For me, I continue caring for them" (P7). (Them: the criminals).

"Thus, we keep doing our jobs sincerely as the code we vowed" (P3).

"Yes, it is. So, the purpose is recovery of the patients, to prevent infection, to recover their wounds. So, the patient's imprisonment is the police officer business and not the nurses 'business" (P2) (Their: the criminals).

The second sub-theme is respecting human dignity. It is described in the following excerpt:

"I always see them from humanitarian grounds" (P8). (Them: The criminals)

"I am feeling sorry for the patient. Although they are guilty the are still human" (P5). (They: The criminals)

The third sub-theme is providing health care without discrimination. It is described in the following excerpt:

"Usually the patients are sent by the police officers. Then, when they arrive in the Emergency Department, we provide equal services just like the other patients" (P4). (They: The criminals)

"Regarding provision of care service, since we work at a hospital, we never discriminate against anyone. Thus, the service must remain based on human needs. It means we are not allowed to discriminate them whether they are criminals or not" $(P 9)$

"All patients are equal because they are patients so we must treat them equally and not look at their status", (P10). (Them: The criminals)

Do not want the police officers to get involved in treating the patients.

This theme describes that the participants did not expect the police officers to provide any nursing interventions for the patients since it would cause inconvenience for the participants. The participants expected them to only accompany the patients but to not get involved in providing interventions for the patients.

This theme is constructed from two sub-themes, they are: feeling that the police officers are not cooperative with the nurses.

"Usually we want to promote a minor surgery, such as suturing. However, there were some police officers denied the anesthesia. They argued to make the patients deterrent" (P10).

"The police officers always intervened. There were also pressures from the police officers" (P1).

"It means we expect cooperate and safely and do not feel like being intimidated by the police officers while performing the treatment" (P7).

"Usually, there were instructions from the police officers. Thus, I, forcefully followed the instructions although I did not want to" (P5).

The second sub-theme is feeling uncomfortable due to the police officer's involvement in providing health care intervention. It is described in the following excerpt:

"It should have been done based on the standard operational procedures that had to be done. However, because there were pressures and intimidations from the police officers, we could not freely and comfortably work due to their pressures and intimidations" (P4).

"We were annoyed at them. We sometimes asked them to not become Mr. Know-It-All since they think they canteach us" (P8). (Them: the police).

"Usually the police officers asked us to work quickly. This possibly makes us uncomfortable because we are asked to do it quickly" (P3).

\section{DISCUSSION}

\section{Awareness of the obligation and responsibility as nurses}

A nurse is a profession that include certain rights, obligations, demands and responsibilities that must be carried out meticulously. This theme describes an awareness of the nurses in carrying out their tasks and obligations in providing nursing treatments for the criminals. Having this responsibility and obligation toward their professions and patients, they were supposed to provide nursing treatments for the 
criminals. They treated them based on the applied standard operating procedures and adhered to the code of conduct in providing nursing treatments for the patients. The nurses were aware of the oath they receive.

Nurses worked on the basis of the standard operational procedure. One of them is a triage procedure. The nurses continue to administer triage procedures for all patients including the criminals. Thus, when the criminals arrive in the Emergency Department, then the patients must undergo the triage procedure. So, when the criminals are in an emergency state condition or critical condition, the nurses prioritize their work and provide quick treatment for all patients. The nurse care is surely based on the triage principle without judging their statuses as the criminals.

The obligation and responsibility of the nurses are written in Undang-Undang No.38 Tahun 2014 about nursing (Nursing law of Indonesia). In the article 37, chapter $b$, it is mentioned that the nurse obligation is to provide service based on the code, nursing service standard, standard operational procedure, and statutory provisions. Based on the constitution, it is seen that the nurses were aware and had been administering nursing services for the criminals based on the nursing law.

Their awareness of their obligations and responsibilities influenced their behaviors and treatments. A study by Susanti (2015) states that awareness of the obligations and responsibilities could influence and improve moral values to act appropriately or inappropriately, to decide and act based on what should have been done. By having awareness of their responsibilities and obligations, those encourage individuals to behave based on their intentions. An individual's behaviors based on their intentions are realizations of their decisions. Their decisions may be influenced by their obligations and rights, code of conduct, or the applied procedure. The final results of individuals' awareness could create self-acceptance, emotion regulation, confidence and discipline improvements, and commitment toward the tasks or obligations.

\section{Practicing the caring principles in treating the criminals}

This research shows that the nurses kept respecting and practicing the caring toward the patients although they were criminals. This theme appears based on the patients' point of view that they had good intentions to help the patients and to ignore their criminalities. The good intentions were expressed while providing optimal treatments for the patients to get better. The nurses stated that even the patients were guilty, but they were still human beings. Their dignities had to be respected and treated humanely.

Caring is applied by the nurses sincerely. The nurses stated that they kept conducting their jobs sincerely. The care given for the patients were all equal both for the criminals and the non-criminals. This research also shows that nurses always struggle to not discriminate against all patients and to treat them fairly without discriminating their statuses or social levels. The nurses realize that caring is an important aspect of promoting nursing interaction between patient-nurses that could support the patients' recoveries.

Several previous findings have supported this theme. A study conducted by Weiskopf (2005) for the patients in a prison showed that the nurses who treated the criminals had high caring or concern. The nurses were frustrated and angry as during their nursing practice their service were limited by the security rules in the prison. The nurses stated that caring is a moral obligation. They also committed towards the respect of the patients' dignity. Meanwhile, a study conducted by Christensen (2014); Courtwright et al. (2008); Smith (2016) stated that individuals that work as nurses not only work to treat the patients but also to caring of them. It refers to the action, the attitude, and the practice to help other people getting a full recovery. Recovery cannot be realized if it does not involve caring.

This finding is also consistent to Watson (1999) theory about caring, stating that human-caring relationship is realized by respecting individuals completely due to their existences in this world. Therefore, the nurses had to improve their effective communication skills toward the patients, so that they could accept their patients completely, honestly, and transparently. The nurses' caring behaviors must include skills to listen, respect, help, support other people's actions, and provide health services for all patients without discriminating them.

Watson's theory of caring has been practiced by the nurses in this research. The nurses perform their compassion and goodness by being aware of the caring value by respecting the patients' dignities. The nurses exist and develop a sincere caring relationship and intention to help the patients to get better from their emergency state conditions and to support their needs.

Empathy is a realization of caring behaviors done by nurses. The empathy of nurses could be realized by 
understanding and feeling what patients experience. It becomes a positive behavior of the nurses so it will influence their nursing treatment practices and the patients' conditions. Showing kindness while treating the patients in a dignified manner through expression of proper gestures, using polite language, being transparent, and display positive expression while providing nursing treatment for the patients can be positive for the patients (Smith, 2016).

\section{They do not want the police officers to get involved in providing treatment for the patients.}

The presence of the police officers in the caring process for the criminals is a useful experience for the nurses. It is because they could assist in the administration and they make the nurses safe during the health administration process for the patients. However, several police officers sometimes made the nurses uncomfortable because they prevent many actions that should have been administered for the patients or in contrast, they wanted the nurses to administer different treatment that should not be done. For example, they prohibited the nurses to administer the anesthesia for the patients. They argued that it was to make them deterrent. The nurses realized that the action was violating the standard operational procedure of nursing. However, because of intimidation and pressures done by the police officers, it made the nurses, by perforce, to follow the police officers' instructions. It made the nurses uncomfortable due to the intervention done by the police officers for the patients.

Such interventions done by the police officers cornered the nurses and brought about limitation in the provision of nursing treatment for the patients. The nurses argued that the police officers were not cooperative and made the nurses conduct actions by forces. Therefore, the nurses demanded that the police officers must only accompany the patients and must not intervene with the nursing intervention for the patients.

A study conducted by Junewicz (2014) found there was $7 \%$ of the nurses that treated the criminals asked the police officers to leave the room during the treatment administration. It was due to the safety reason of the nurses. However, this study also showed that police officers frequently interrupted the treatment process given by the nurses, especially in violating privacy. This theme is supported by Zust et al. (2013) found that one of the challenges in providing treatment for criminals was from the police officers that escorted the criminals. The police officers escorting the criminals are considered to hinder the nursing process, the patients' resting times, break their privacies, and even commit cruel action for the criminals.

Furthermore, a study by Weiskopf (2005) found that nurses were frustrated by the existence of the police officers that limited them to provide nursing interventions for the patients, This condition could degrade the nursing care quality given to the patients. The nurses wanted to accentuate the patients but several police officers did not understand the treatment. They limited the given service quality by the nurses. This study shows that when the police officers respected the applied nursing process, they would feel like being supported and having the independence to make clinical decisions.

The nurses carrying out the treatments for the criminals should develop a proper relationship with the police officers. The police officers should improve their attitudes towards the nurses, and they must cooperate with nurses although they had different roles to play. Thus, the police officers could defer the authority towards nurses, respect nurses, support them, and avoid getting involved in providing nursing treatments for them. This is expected to improve the authority and independence of the nurses as well as their conveniences while providing nursing treatments for the criminals (Weiskopf, 2005).

\section{CONCLUSION}

Treating criminals pose a different challenge for the nurses. For the nurses, it would be difficult to treat and care a patient who had done criminal offence, ravishment, and assassination. This research shows that while providing nursing treatment for the criminals, the nurses had to be professional and not to be affected by the patients' criminality backgrounds. The nurses were aware of their responsibilities and obligations as nurse and continue practicing the caring procedure as the philosophy of nursing. The nurses expected the police officers escorting the criminals not to provide nursing intervention for the patients because it could make the nurses uncomfortable. Therefore, it is important for the nurses to get involved and to reflect their caring practices in providing nursing treatments to achieve complete cure and reach the purpose of nursing.

\section{Conflict of Interests}

The authors declare that they have no conflict of interest.

\section{ACKNOWLEDGEMENT}

Thanks to all participants who voluntarily participated in this research. 


\section{REFERENCES}

Christensen, S. (2014). Enhancing nurses' ability to care within the culture of incarceration. Journal of Transcultural Nursing, 25(3), pp 223-231.

Courtwright, A., Raphael, T. \& Collichio, F. (2008). Shackled: The challenge of caring for an incarcerated patient. American Journal of Hospice \& Palliative Medicine, 25(1), pp 315-317.

Creswell, J.W. (2014). Research design: Quantitative, qualitative and mixed methods approaches, $4^{\text {th }}$ edition. SAGE Publications, California.

Dhaliwal, K. \& Hirst, S. (2016). Caring in correctional nursing: A systematic search and narrative synthesis. Journal of Forensic Nursing, 12(1), pp 5-12.

Junewicz, A. (2014). Shackled: providing health care to prisoners outside of prison. The American Journal of Bioethics, 14(7), pp 2013-2014.

Maeva, M. K. \& Vaughn, M. S. (2001). Nursing with prisoners: the practice of caring, forensic nursing or penal harm nursing. Advances in Nursing Science, 24(2), pp 47-64.

Margalith, I., Tabak, N. \& Granot, T. (2008). Student nurses' care of terrorists and their victims. Nursing Ethics, 15(5), pp 601-613.

McConville, S., Mooney, C., Williams, A. \& Hsia, Y. (2018). How do ED patients with criminal justice contact compare with other ED users? Aretrospective analysis of ED visits in California. BMJOpen, 8(1), pp 1-8.

Melillo, K. D. (2009). Caring for incarcerated older adults, aging, mental health, and incarceration. Journal of Gerontological Nursing, 35(1), pp 3-6.

Nursing Law of Indonesia (2014). Undang-undang keperawatan no. 37 b, pp 8-9.

Redgewell, S. (2010). Patient or prisoner? Caring in a secure environment. Criminal justice Matters, 81(1), pp 6-7.

Smith, F. D. (2016). Perioperative care of prisoners: providing safe care. Association of Registered Nurses Journal, 103(3), pp 282-288.

Smith, J.A. \& Osborn, M. (2008). Interpretative phenomenological analysis. Qualitative Psychology, 2(1), pp 53-80.

Susanti, R. H. (2015). Meningkatkan kesadaran tanggung jawab siswa SMP melalui penggunaan teknik klarifikasi nilai. Journal Konseling Indonesia, 1(1), pp 38-46.

United Nations Office on Drug and Crime (2019). Retrived from: https://www. unodc.org/unodc/en/data-andanalysis/crimedata.html.

Watson, J. (1999). Postmodern nursing and beyond. Churchill Livingstones, Edinburgh.

Weiskopf, C. S. (2005). Nurses' experience of caring for inmate patients. Journal of Advanced Nursing, 49(4), pp 336-343.

Zust, B. L., Busiahn, L. \& Janisch, K. (2013). Nurses' experiences caring for incarcerated patients in a perinatal unit. Issues in Mental Health Nursing, 34(1), pp 25-29. 